\title{
Profile of Dr. Xu Zhang
}

Dr. Xu Zhang was conferred the Bachelor's degree of Medicine from Fourth Military Medical University in 1985. From 1990 to 1994, he carried out his Ph.D. study at the Department of Neuroscience, Karolinska Institute in Sweden. Then, he was appointed as lecturer, associate professor and professor successively at the Institute of Neuroscience, Fourth Military Medical University. In 1999, he was recruited as a principal investigator by the Institute of Neuroscience, Chinese Academy of Science. He received the outstanding young investigator award of National Natural Science Foundation of China in 1995. He was elected as Academician of Chinese Academy of Sciences in 2015.

Dr. Zhang's research is mainly focused on the molecular and cellular mechanisms of neural diseases, such as chronic pain and X-linked intellectual disability. He has found the changes in gene expression patterns of somatosensory ganglia and the spinal cord after nerve injury and inflammation, and several important mechanisms for regulating the functions of neuropeptides, opioid receptors, $\mathrm{Na}^{+} / \mathrm{K}^{+}$pump and voltage-gated sodium channel in the nociceptive sensory neurons. He has also explored the genes related to mental retardation and their underlying mechanisms.

\section{ESTABLISHMENT OF GENE EXPRESSION PROFILES RELATED TO CHRONIC PAIN}

Based on the idea that the change of gene expression in the spinal circuits could lead to chronic pain, Dr. Zhang's research group developed rat cDNA arrays and demonstrated that the expression of the genes encoding channels, receptors and signal transduction-related molecules was strongly regulated in the dorsal root ganglion (DRG) and the spinal dorsal horn after peripheral nerve injury (Xiao et al., 2002). They constructed the cDNA libraries of lumbar DRGs of normal rats and of rats 14 days after peripheral axotomy, and provided the first unigene library of DRGs. These studies provide evidence that peripheral nerve injury induces distinct gene profiles in both the DRG and spinal dorsal horn. A series of studies reveals the rules of a number of molecules identified by analyzing the gene expression profiles in the analgesic targets, and therefore provides a theo-

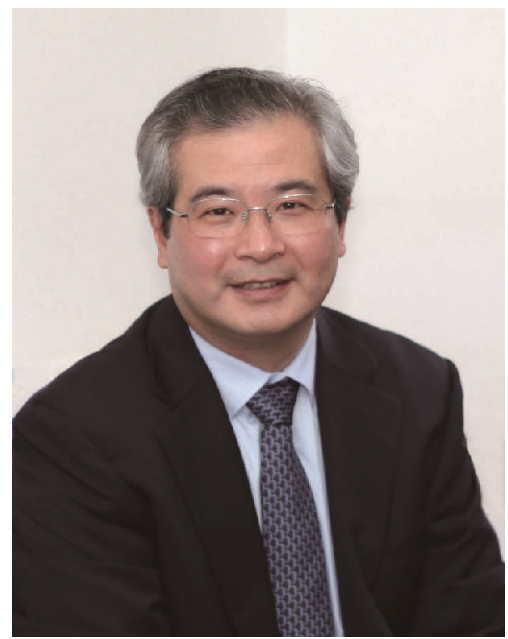

retical basis for clinical pain treatment and analgesic development. The results have been edited into the Wall and Melzack's Textbook of Pain.

\section{DEFINITION OF SOMATOSENSORY NEURON TYPES}

Dr. Zhang's research group developed single-cell RNA-sequencing technique to identify the types of mouse DRG neurons and the neuron type-specific marker genes, and determined the functions of DRG neuron types by their responses to peripheral stimuli (Li et al., 2016). They showed that small-diameter DRG neurons were classified into one type of low-threshold mechanoreceptor and five types of mechanoheat nociceptors (MHNs). Each of the MHN types was further categorized into two subtypes. Large DRG neurons are categorized into four types. This study provides a new system for cataloging somatosensory neurons and their transcriptome databases.

\section{EXPLORATION OF NOVEL MECHANISMS INVOLVED IN PAIN REGULATION}

Based on the idea that the genes highly expressed in nociceptive neurons and changed in chronic pain conditions 
might be involved in the pain modulation, Dr. Zhang's group explores novel pain-related modulators. They found that follistatin-like 1 (FSTL1) highly expressed in small DRG neurons was released from nociceptive afferent terminals and negatively regulated sensory transmission by activating the presynaptic $\alpha 1$ subunit of $\mathrm{Na}^{+}, \mathrm{K}^{+}$-ATPase $\left(\mathrm{Na}^{+} / \mathrm{K}^{+}\right.$pump) (Li et al., 2011). They also showed that the expression of FSTL1 in DRG neurons was down-regulated after peripheral nerve injury and application of FSTL1 could inhibit nerve injury-induced pain hypersensitivity. These findings provide FSTL1 as a first endogenous NKA agonist that regulates synaptic transmission. Furthermore, they also revealed that the FXYD2/ 1 NKA interaction increased after inflammation, resulting in reduction of NKA activity, depolarization of neuron membrane and facilitation of excitatory afferent neurotransmission (Wang et al., 2015), revealing a fundamental mechanism underlying the persistent inflammatory pain.

Dr. Zhang's group also detected that B-type natriuretic peptide (BNP) negatively regulated nociceptive transmission and inhibited inflammatory pain through activating presynaptic receptor and opening large-conductance $\mathrm{Ca}^{2+}$-activated $\mathrm{K}^{+}$channels $\left(\mathrm{BK}_{\mathrm{Ca}}\right.$ channels) in nociceptive afferent neurons (Zhang et al., 2010). Moreover, they found that the DRG-expressed activin $\mathrm{C}$ reduced the inflammation-induced phosphorylation of extracellular signal-regulated kinase and suppressed inflammatory pain (Liu et al., 2012). A series of works reveals a self-inhibitory system regulating pain sensation in DRG neurons.

Recently, Dr. Zhang's group discovered that fibroblast growth factor 13 (FGF13) is highly expressed in the mechanoheat nociceptors of adult mice and selectively regulates heat nociception (Yang et al., 2017). Moreover, FGF13/ $\mathrm{Na}_{\mathrm{v}} 1.7$ interaction is a critical mechanism for heat nociception. These findings provide a new concept about the pain mechanism and a novel pain therapeutic target.

\section{IDENTIFICATION OF OPIOID RECEPTOR INTERACTION AND ITS ROLE REGULATING MORPHINE ANALGESIA}

Dr. Zhang's group carried out extensive investigation on the interaction between $\mu$ and $\delta$ opioid receptors, and related functions. They provided direct evidence supporting the co-expression of $\mu$ and $\delta$ opioid receptors in nociceptive DRG neurons (Wang et al., 2010). They detected that $\delta$ opioid receptors could be localized and trafficking in the large-dense core vesicles (LDCVs), enabling the stimulus-induced cell surface expression of these receptors, while $\mu$ opioid receptors were constitutively expressed on the cell surface (Bao et al., 2003). Moreover, they found that $\delta$ opioid receptors could be sorted into LDCVs via an interaction with protachykinin, and established a relationship of the receptor membrane insertion with the morphine analgesic tolerance (Guan et al., 2005). Beside the localization of $\delta$ opioid receptors in LDCV of DRG neurons, they detected that LDCVs also contained $\delta$ opioid receptor-associated signaling molecule complex, other receptors and ion channels (Zhao et al., 2011), providing the evidence for activity-dependent membrane insertion of receptors and ion channels.

Dr. Zhang proposed a model of the correlation between the ratio of surface $\mu$ and $\delta$ opioid receptors and the development of morphine tolerance (Zhang et al., 2006). To explore the relationship of opioid receptor interaction with morphine tolerance, they found that activation of $\delta$ opioid receptor caused co-internalization and co-degradation of $\mu$ and $\delta$ opioid receptors, and the dissociation of these two receptors reduced morphine tolerance (He et al., 2011). This study was listed as a feature article and one of the articles in "pain and itch" topic of Neuron in 2011. Dr. Zhang group's studies provided a notion that an interaction of $\mu$ and $\delta$ opioid receptors regulates opioid analgesia, which represents a new direction of the function of receptor complex and drug discovery (Zhang et al., 2015).

\section{CORRECTION OF THE STRUCTURAL BASIS DURING DEVELOPMENT OF NEUROPATHIC PAIN}

Peripheral axotomy-induced sprouting of thick myelinated afferents (A-fibers), which mainly mediate the touch and pressure sensation, from the laminae III-IV of spinal cord into the pain-processing laminae I-II was a well-established hypothesis for the structural basis of nerve injury-induced neuropathic pain in the 1990s. Dr. Zhang's group clarified that axotomy-induced sprouting from deeper to superficial layers of spinal dorsal horn is much less pronounced than previously assumed (Bao et al., 2002). This finding has been edited into the Wall and Melzack's Textbook of Pain.

\section{IDENTIFICATION OF GENES RELATED TO MENTAL RETARDATION AND UNDERLYING MECHANISMS}

Dr. Zhang's research group found that a candidate gene for the X-linked mental retardation, FGF13, was expressed in cerebral cortical neurons during the brain development $(\mathrm{Wu}$ et al., 2012). The splicing isoform FGF13B was a microtubule-stabilizing protein required for axon/leading process development and neuronal migration in the cerebral cortex. Loss of FGF13B in cortical neurons impaired the transition from the multipolar to bipolar stage, and increased the branching of axons and leading processes. FGF13-deficient mice showed the neuron migration defects in both the neocortex and the hippocampus, and weakened spatial learning and memory. These findings not only reveal an important function of non-secretory FGF but also clarify the mechanism of mental retardation related with FGF13 defect. This 
study is considered as one of the studies that set the stage for the subsequent studies that have provided a more extensive picture of the complex molecular orchestra that mediates development of the cerebral cortex and how its disruption contributes to disease.

Dr. Zhang is an outstanding neuroscientist with international reputation. He has published more than one hundred research articles and invited reviews, and was invited to be a contributing author in Wall and Melzack's Textbook of Pain. He gave many invited lectures at the international meetings, including a plenary lecture at 9th World Congress of International Brain Research Organization. He was also honored several awards including the Science and Technology Progress Prize from Ho Leung Ho Lee Foundation. Dr. Zhang has made a great contribution to Chinese and international societies of neuroscience and cell biology. $\mathrm{He}$ co-chaired the 9th "International Association for the Study of Pain" Research Symposium and the 4th Asian Pain Symposium. He serves as vice presidents of Chinese Neuroscience Society and Chinese Society for Cell Biology, and president of Shanghai Society for Neuroscience.

Compliance and ethics The author(s) declare that they have no conflict of interest.

Bao, L., Jin, S., Zhang, C., Wang, L., Xu, Z., Zhang, F., Wang, L., Ning, F., Cai, H., Guan, J., Xiao, H., Xu, Z., He, C., Hökfelt, T., Zhou, Z., and Zhang, X. (2003). Activation of delta-opioid receptors induces receptor insertion and neuropeptide secretion. Neuron 37, 121-133.

Bao, L., Wang, H., Cai, H., Tong, Y., Jin, S., Lu, Y., Grant, G., Hökfelt, T., and Zhang, X. (2002). Peripheral axotomy induces only very limited sprouting of coarse myelinated afferents into inner lamina II of rat spinal cord. Eur J Neurosci 16, 175-185

Guan, J., Xu Z., Gao, H., He, S., Ma, G., Sun, T., Wang, L., Zhang, Z., Lena, I., Kitchen, I., Elde, R., Zimmer, A., He, C., Pei, G., Bao, L. and Zhang X. (2005). Interaction with vesicle luminal protachykinin regulates surface expression of $\delta$-opioid receptors and opioid analgesia. Cell 122, 619-631.

He, S., Zhang, Z., Guan, J., Liu, H., Zhao, B., Wang, H., Li, Q., Yang, H., Luo, J., Li, Z., Wang, Q., Lu, Y., Bao, L., and Zhang, X. (2011). Facilitation of $\mu$-opioid receptor activity by preventing $\delta$-opioid recep- tor-mediated codegradation. Neuron 69, 120-131.

Li, C., Li, K., Wu, D., Chen, Y., Luo, H., Zhao, J., Wang, S., Sun, M., Lu, Y., Zhong, Y., Hu, X., Hou, R., Zhou, B., Bao, L., Xiao, H., and Zhang, $X$. (2016). Somatosensory neuron types identified by high-coverage single-cell RNA-sequencing and functional heterogeneity. Cell Res 26, 83-102.

Li, K., Zhang, F., Li, C., Wang, F., Yu, M., Zhong, Y., Zhang, K., Lu, Y., Wang, Q., Ma, X., Yao, J., Wang, J., Lin, L., Han, M., Zhang, Y., Kuner, R., Xiao, H., Bao, L., Gao, X., and Zhang, X. (2011). Follistatin-like 1 suppresses sensory afferent transmission by activating $\mathrm{Na}^{+}$, $\mathrm{K}^{+}$-ATPase. Neuron 69, 974-987.

Liu, X., Zhang, F., Liu, H., Li, K., Lu, Y., Wu, Q., Li, J., Wang, B., Wang, Q., Lin, L., Zhong, Y., Xiao, H., Bao, L., and Zhang, X. (2012). Activin $\mathrm{C}$ expressed in nociceptive afferent neurons is required for suppressing inflammatory pain. Brain 135, 391-403.

Wang, F., Cai, B., Li, K., Hu, X., Lu, Y., Wang, Q., Bao, L., and Zhang, X. (2015). FXYD2, a $\gamma$ subunit of $\mathrm{Na}^{+}, \mathrm{K}^{+}$-ATPase, maintains persistent mechanical allodynia induced by inflammation. Cell Res 25, 318-334.

Wang, H., Zhao, B., Zhong, Y., Li, K., Li, Z., Wang, Q., Lu, Y., Zhang, Z., He, S., Zheng, H., Wu, S., Hökfelt, T.G., Bao, L., and Zhang, X. (2010). Coexpression of $\delta$ - and $\mu$-opioid receptors in nociceptive sensory neurons. Proc Natl Acad Sci USA 107, 13117-13122.

Wu, Q., Yang, L., Li, S., Wang, Q., Yuan, X., Gao, X., Bao, L., and Zhang, X. (2012). Fibroblast growth factor 13 is a microtubule-stabilizing protein regulating neuronal polarization and migration. Cell 149, 1549-1564.

Xiao, H., Huang, Q., Zhang, F., Bao, L., Lu, Y., Guo, C., Yang, L., Huang, W., Fu, G., Xu, S., Cheng, X., Yan, Q., Zhu, Z., Zhang, X., Chen, Z., Han, Z., and Zhang, X. (2002). Identification of gene expression profile of dorsal root ganglion in the rat peripheral axotomy model of neuropathic pain. Proc Natl Acad Sci USA 99, 8360-8365.

Yang, L., Dong, F., Yang, Q., Yang, P., Wu, R., Wu, Q., Wu, D., Li, C., Zhong, Y., Lu, Y., Cheng, X., Xu, F., Chen, L., Bao, L., and Zhang, X. (2017). FGF13 selectively regulates heat nociception by interacting with $\mathrm{Na}_{\mathrm{v}}$ 1.7. Neuron 93, 806-821.

Zhang, F., Liu, X., Gong, L., Yao, J., Li, K., Li, Z., Lin, L., Lu, Y., Xiao, H., Bao, L., Zhang, X., and Zhang, X. (2010). Inhibition of inflammatory pain by activating B-Type natriuretic peptide signal pathway in nociceptive sensory neurons. J Neurosci 30, 10927-10938.

Zhang, X., Bao, L., and Guan, J. (2006). Role of delivery and trafficking of delta-opioid peptide receptors in opioid analgesia and tolerance. Trends Pharmacol Sci 27, 324-329.

Zhang, X., Bao, L., and Li, S. (2015). Opioid receptor trafficking and interaction in nociceptors. Br J Pharmacol 172, 364-374.

Zhao, B., Wang, H., Lu, Y., Hu, J., Bao, L., and Zhang, X. (2011). Transport of receptors, receptor signaling complexes and ion channels via neuropeptide-secretory vesicles. Cell Res 21, 741-753. 